\title{
Triterpenoid Saponins from the Roots of Sophora koreensis
}

\author{
Ji Hye Byun, ${ }^{a}$ Ju Sun KIm, ${ }^{a}$ Sam Sik Kang, ${ }^{*, a}$ Kun Ho Son, ${ }^{b}$ Hyeun Wook Chang, ${ }^{c}$ Hyun Pyo KIm, ${ }^{d}$ \\ and KiHwan $\mathrm{BAE}^{e}$ \\ ${ }^{a}$ Natural Products Research Institute and College of Pharmacy, Seoul National University; Seoul 110-460, Korea: \\ ${ }^{b}$ Department of Food and Nutrition, Andong National University; Andong 760-749, Korea: ${ }^{c}$ College of Pharmacy, \\ Yeungnam University; Gyongsan 712-749, Korea: 'College of Pharmacy, Kangwon National University; Chuncheon \\ 200-749, Korea: and ${ }^{e}$ College of Pharmacy, Chungnam National University; Taejon 305-764, Korea.
}

Received February 24, 2004; accepted March 26, 2004

From the roots of Sophora koreensis (Fabaceae), three new oleanene-type triterpene glycosides, echinosophorosides $A_{1}$ (1) and B (2), and acetyl-subproside II (5), were isolated as their methyl esters, together with the four known ones sophoraflavoside I, kudzusaponin $\mathbf{S A}_{3}$, subproside II, and azukisaponin V. The structures of the new saponins were elucidated to be $3-O$ - $\alpha$-L-rhamnopyranosyl $(1 \rightarrow 2)-\alpha$-L-arabinopyranosyl $(1 \rightarrow 2)$ - $\beta$-D-glucuronopyranosyl kudzusapogenol A 22- $O$ - $\alpha$-L-arabinopyranoside (1), 3- $O$ - $\alpha$-L-rhamnopyranosyl(1 $\rightarrow 2)$ - $\alpha$-L-arabinopyranosyl-(1 $\rightarrow 2)$ - $\beta$-D-glucuronopyranosyl abrisapogenol $\mathrm{C}$ 22- $O$ - $\alpha$-L-arabinopyranoside (2), and 3-O- $\alpha$-Lrhamnopyranosyl $(1 \rightarrow 2)$ - $\alpha$-L-arabinopyranosyl $(1 \rightarrow 2)$ - $\beta$-D-glucuronopyranosyl kudzusapogenol A 22-O-acetate (5), respectively. It is noteworthy that two arabinopyranosyl moieties in the same molecule, echinosophoroside B (2), have different conformations. The conformation of the arabinopyranosyl moiety existing in the trisaccharide moiety was determined to be ${ }^{1} C_{4}$, whereas that of the arabinopyranosyl unit at C-22 was identified as ${ }^{4} C_{1}$.

Key words Sophora koreensis; Fabaceae; triterpenoid saponin; echinosophoroside

Sophora koreensis NAKAI (syn. Echinosophora koreensis NAKAI = Keyserlingia koreensis NAKAI) (Fabaceae) is a perennial nonclimbing shrub native to Korea. ${ }^{1)}$ This plant bears characteristic four-winged fruit. ${ }^{2)}$ There have been several reports on the isolation of flavonoids, ${ }^{3-7)}$ a coumarin, ${ }^{5,8)}$ alka-

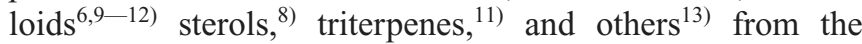
roots, flowers, and aerial parts of this plant. In a previous paper, ${ }^{7)}$ we reported on the isolation and structure elucidation of a saponin, kudzusaponin $\mathrm{A}_{3},{ }^{14,15)}$ from this plant. Further study on this plant has yielded four known saponins, sophoraflavoside I (3), kudzusaponin $\mathrm{SA}_{3}$ (4) subproside II (6), and azukisaponin $\mathrm{V}$ (7) and three new saponins, which we have called echinosophorosides $A_{1}$ (1) and $B(2)$, and acetyl-subproside II (5). We report here the isolation and structure determination of these saponins.

The dried and powdered roots of S. koreensis was extracted and partitioned as described in the Experimental section. Methylation of the $n$-butanol $(\mathrm{BuOH})$ fraction with $\mathrm{CH}_{2} \mathrm{~N}_{2}$, followed by successive chromatography using silica, Sephadex LH-20, and reverse-phase $\mathrm{C}_{18}$ afforded compounds $1-7$ as their methyl esters. The structures of these isolated compounds were established through analysis of their NMR and MS spectra, which enabled the characterization of compounds 1, 2, and 5 as novel and compounds 3, 4, 6, and 7 as known. Spectra for known saponins confirmed their structures to be sophoraflavoside I (3), kudzusaponin $\mathrm{SA}_{3}$ (4), subproside II (6), and azukisaponin V (7).

Echinosophoroside $A_{1}$ methyl ester (1a) was obtained as an amorphous powder. High-resolution (HR) FAB-MS gave the composition $\mathrm{C}_{53} \mathrm{H}_{86} \mathrm{O}_{23}$. An inspection of the ${ }^{1} \mathrm{H}$ - and ${ }^{13} \mathrm{C}$ NMR spectra of the compound readily indicated the presence of four monosaccharide units through easily identifiable signals for anomeric protons and carbons. Acid hydrolysis of 1a afforded kudzusapogenol A $(3 \beta, 21 \beta, 22 \beta, 24,29$-pentahydroxyolean-12-ene $)^{16}$ as an aglycon and arabinose, rhamnose, and glucuronic acid as the sugar components identified on TLC analysis by comparison with authentic samples. Ab-

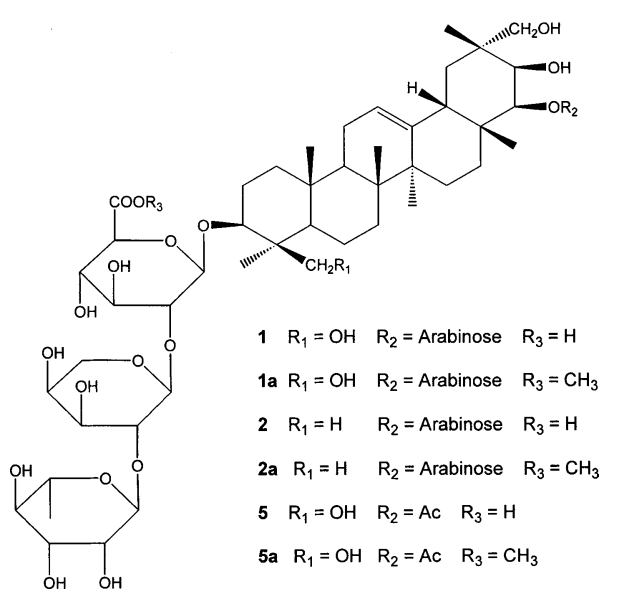

solute configurations for sugars were determined to be the Lform except for glucuronic acid (D-form), according to the procedure developed by Hara et al. ${ }^{17)}$ The negative-ion mode FAB mass spectrum of 1a exhibited an $[\mathrm{M}-\mathrm{H}]^{-}$ion at $\mathrm{m} / \mathrm{z}$ 1089 which is consistent with a tetrasaccharide glycoside carrying two arabinose, one rhamnose, one glucuronic acid methyl ester, and an aglycon with a molecular mass of 490 . Comparison of the ${ }^{13} \mathrm{C}$-NMR data of the aglycon moiety of 1a with kudzusapogenol $\mathrm{A}^{16)}$ showed that the signals for $\mathrm{C}-3$ and C-22 of 1a were significantly shifted downfield by +11.3 and $+13.8 \mathrm{ppm}$, respectively, due to a glycosidation shift. ${ }^{18)}$ The ${ }^{13} \mathrm{C}$-NMR spectrum of 1a was superimposable on that of kudzusaponin $\mathrm{A}_{1}{ }^{15)}$ except for the xylopyranosyl signals at C-22 which were substituted for by the arabinopyranosyl moiety in 1a. From these observations, it was deduced that 1a was a 3,22-bisdesmoside of kudzusapogenol A with four units of sugar. The ${ }^{1} \mathrm{H}-{ }^{1} \mathrm{H}$ correlation spectroscopy (COSY) experiment with 1a allowed the sequential assignments of four monosaccharides. Their multiplet patterns and coupling constants allowed the identification of an $\alpha$-L-arabinopyranosyl $\left({ }^{4} C_{1}\right), \alpha$-L-rhamnopyranosyl $\left({ }^{1} C_{4}\right)$, and $\beta$-D-glucurono- 


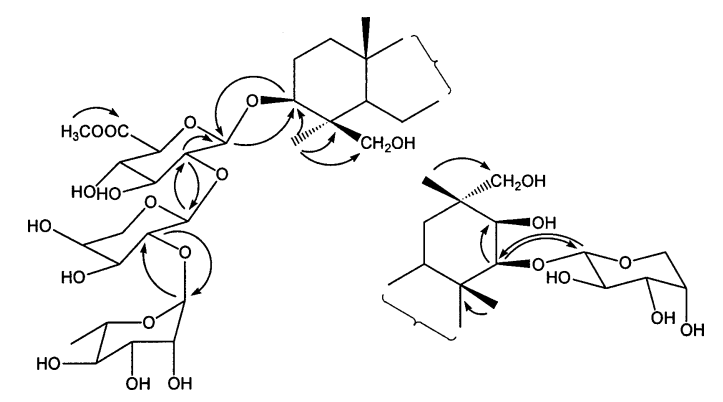

Fig. 1. Key Correlations for the Echinosophoroside $A_{1}$ Methyl Ester (1a) Observed in the HMBC Spectrum

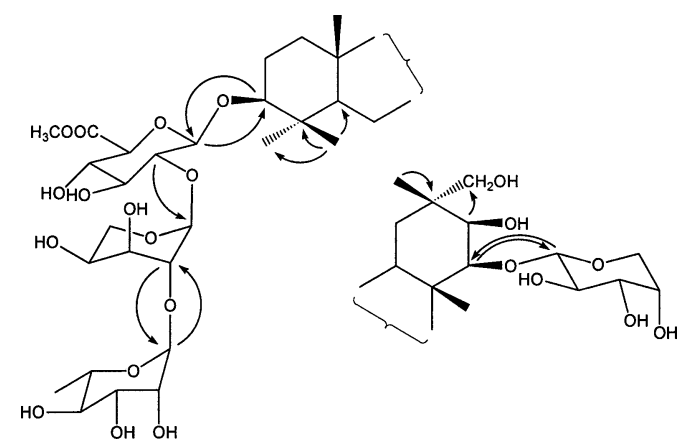

Fig. 2. Key Correlations for the Echinosophoroside B Methyl Ester (2a) Observed in the HMBC Spectrum

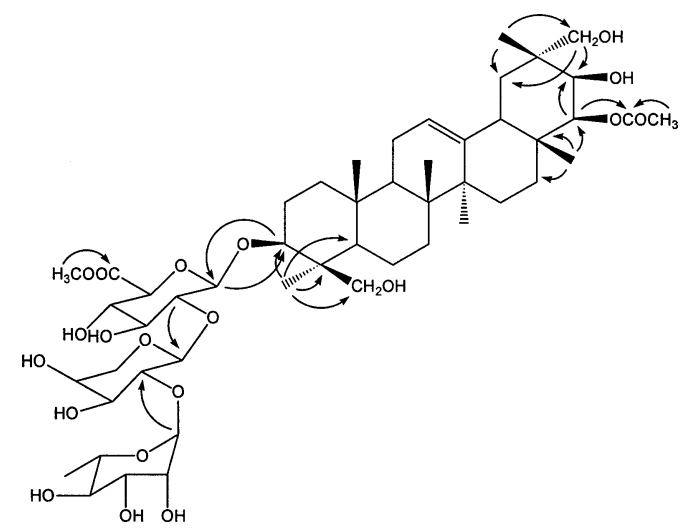

Fig. 3. Key Correlations for the Acetyl-Subproside II Methyl Ester (5a) Observed in the HMBC Spectrum

Table 1. ${ }^{1}$ H-NMR Data of Aglycon Moieties of 1a, 2a, and 5a

\begin{tabular}{llll}
\hline \hline Proton no. & \multicolumn{1}{c}{$\mathbf{1 a}$} & \multicolumn{1}{c}{ 2a } & \multicolumn{1}{c}{ 5a } \\
\hline $23-\mathrm{CH}_{3}$ & $1.40(\mathrm{~s})$ & $1.31(\mathrm{~s})$ & $1.41(\mathrm{~s})$ \\
$24-\mathrm{CH}_{3}$ & - & $1.14(\mathrm{~s})$ & - \\
$25-\mathrm{CH}_{3}$ & $0.71(\mathrm{~s})$ & $0.85(\mathrm{~s})$ & $0.73(\mathrm{~s})$ \\
$26-\mathrm{CH}_{3}$ & $0.93(\mathrm{~s})$ & $0.98(\mathrm{~s})$ & $0.91(\mathrm{~s})$ \\
$27-\mathrm{CH}_{3}$ & $1.35(\mathrm{~s})$ & $1.34(\mathrm{~s})$ & $1.31(\mathrm{~s})$ \\
$28-\mathrm{CH}_{3}$ & $1.41(\mathrm{~s})$ & $1.42(\mathrm{~s})$ & $1.02(\mathrm{~s})$ \\
$30-\mathrm{CH}_{3}$ & $1.47(\mathrm{~s})$ & $1.48(\mathrm{~s})$ & $1.44(\mathrm{~s})$ \\
$\mathrm{H}-3$ & $3.36(\mathrm{dd}, 4.5,12.0)$ & $3.31(\mathrm{dd}, 4.5,12.0)$ & $3.36(\mathrm{dd}, 4.0,12.0)$ \\
$\mathrm{H}-12$ & $5.36(\mathrm{t}-\mathrm{like}, 3.5)$ & $5.35(\mathrm{t}-\mathrm{like}, 3.5)$ & $5.35(\mathrm{t}-1 \mathrm{ke}, 3.5)$ \\
$\mathrm{H}-21$ & $4.59(\mathrm{brs})$ & $4.60(\mathrm{overlap})$ & $4.62(\mathrm{~d}, 2.1)$ \\
$\mathrm{H}-22$ & $3.88(\mathrm{~d}, 3.0)$ & $3.88(\mathrm{~d}, 2.5)$ & $5.44(\mathrm{~d}, 2.1)$ \\
$\mathrm{H}-24$ & $3.28(\mathrm{brd}, 11.5)$ & - & $3.29(\mathrm{brd}, 10.5)$ \\
& $4.27(\mathrm{~d}, 11.5)$ & & $4.27(\mathrm{~d}, 11.0)$ \\
$\mathrm{H}-29$ & $3.56(\mathrm{~d}, 10.5)$ & $3.57(\mathrm{~d}, 11.0)$ & $3.61(\mathrm{~d}, 10.5)$ \\
& $4.13(\mathrm{~d}, 10.5)$ & $4.12(\mathrm{~d}, 11.0)$ & $4.08(\mathrm{~d}, 10.5)$ \\
Acetate & & & $2.17(\mathrm{~s})$ \\
\hline
\end{tabular}

pyranosyl $\left({ }^{4} C_{1}\right)$ unit. The arabinosyl unit was shown to be directly attached at $\mathrm{C}-22$ of the aglycon by an heteronuclear multiple-bond correlation (HMBC) between the signals of the anomeric proton of the arabinosyl unit at $\delta 4.92$ and C-22 of the aglycon at $\delta$ 93.9. The anomeric proton of the rhamnosyl moiety at $\delta 6.22$ showed a ${ }^{3} J_{\mathrm{C}, \mathrm{H}}$ correlation with C-2 of the arabinosyl residue at $\delta 78.0$, the anomeric proton of which at $\delta 5.56$ in turn showed a long-range correlation with $\mathrm{C}-2$ of the glucuronosyl moiety at $\delta 76.8$. The long-range correlation between the $\mathrm{C}-3$ resonance at $\delta 91.4$ and the anomeric proton signal of the glucuronosyl unit at $\delta 4.94$ confirmed the attachment of the glucuronosyl moiety at C-3 of the aglycon. In light of the above observations, the structure of the echinosophoroside $A_{1}$ (1) was determined to be 3$O$ - $\alpha$-L-rhamnopyranosyl $(1 \rightarrow 2)-\alpha$-L-arabinopyranosyl $(1 \rightarrow 2)$ $\beta$-D-glucuronopyranosyl kudzusapogenol A 22- $O$ - $\alpha$-L-arabinopyranoside.

Echinosophoroside B methyl ester (2a) was shown to have the molecular formula $\mathrm{C}_{53} \mathrm{H}_{86} \mathrm{O}_{22}$ on the basis of the (-)-HRFAB-MS. Acid hydrolysis of $\mathbf{2 a}$ gave an aglycon identified as abrisapogenol $\mathrm{C}(3 \beta, 21 \beta, 22 \beta, 29$-tetrahydroxyolean-12ene $)^{19)}$ and sugars identified as L-arabinose, L-rhamnose, and D-glucuronic acid as described in 1a. ${ }^{17)}$ The sequence of the sugars and binding sites at the aglycon of $\mathbf{2 a}$ were determined based on two-dimensional (2D) NMR experiments. These results indicate that $\mathbf{2} \mathbf{a}$ has the same sequence of sugar linkages as 1a. In the ${ }^{13} \mathrm{C}-\mathrm{NMR}$ spectrum, the signal due to the C-24 hydroxymethyl carbon at $\delta 63.8$ in 1a was displaced by a methyl carbon at $\delta 17.3$ in $\mathbf{2 a}$. All other signals were almost completely superimposable between $\mathbf{1 a}$ and $\mathbf{2 a}$, with the exception of signals for arabinopyranosyl and glucuronopyranosyl moieties linked at C-3 of the aglycon. It is interesting that the anomeric ${ }^{3} J_{\mathrm{H}-1, \mathrm{H}-2}$ coupling constant of the inner arabinopyranosyl moiety in $\mathbf{2} \mathbf{a}$ was smaller than that of other arabinopyranosyl units in 1a and 2a. This result suggests that the conformation of this arabinopyranosyl moiety is different from that of the other arabinopyranosyl moieties in 1a and 2a. The small ${ }^{3} J_{\mathrm{H}-1, \mathrm{H}-2}$ coupling constant $(3.0 \mathrm{~Hz})$ for the anomeric proton of the arabinopyranosyl moiety of the trisaccharide chain at $\mathrm{C}-3$ suggests that it has a ${ }^{1} C_{4}$ conformation rather than the usual ${ }^{4} C_{1}$ conformation. ${ }^{20-22)}$ Furthermore, the other coupling constants assignable to the remaining signals for the arabinopyranosyl moiety were in good agreement with those reported in the literature. ${ }^{20,22)}$ Thus the structure of the echinosophoroside B (2) was determined to be $3-O-\alpha$-L-rhamnopyranosyl $(1 \rightarrow 2)$ - $\alpha$-L-arabinopyranosyl $(1 \rightarrow 2)-\beta$-D-glucuronopyranosyl abrisapogenol C 22 $O$ - $\alpha$-L-arabinopyranoside.

The HR-FAB-MS of acetyl-subproside II methyl ester (5a) displayed an $[\mathrm{M}-\mathrm{H}]^{-}$ion at $m / z$ 999.5160, which was consistent with the molecular formula as $\mathrm{C}_{50} \mathrm{H}_{80} \mathrm{O}_{20}$. Acid hydrolysis of $\mathbf{5 a}$ gave kudzusapogenol $\mathrm{A}^{16)}$ and L-arabinose, Lrhamnose, and D-glucuronic acid. The NMR spectra of compound $\mathbf{5 a}$ were similar to those of $\mathbf{1 a}$, with a major difference due to the absence of one of the sugars as indicated by the lack of anomeric proton and carbon signals at $\delta 4.92$ and 109.3, respectively. The presence of an acetyl group in 5a was confirmed by the NMR signals at $\delta 2.17$ in the ${ }^{1} \mathrm{H}-\mathrm{NMR}$ and $\delta 21.6$ and 171.3 in ${ }^{13} \mathrm{C}$-NMR spectra. The site of attachment and the sequence in the monosaccharide chain were confirmed through the analysis of the HMBC spectrum of 
Table 2. NMR Data of Sugar Moieties of 1a, 2a, and 5a

\begin{tabular}{|c|c|c|c|c|c|c|}
\hline \multirow{2}{*}{ No. } & \multicolumn{2}{|l|}{ 1a } & \multicolumn{2}{|l|}{$2 a$} & \multicolumn{2}{|l|}{$5 a$} \\
\hline & $\delta_{\mathrm{H}}$ & $\delta_{\mathrm{C}}$ & $\delta_{\mathrm{H}}$ & $\delta_{\mathrm{C}}$ & $\delta_{\mathrm{H}}$ & $\delta_{\mathrm{C}}$ \\
\hline \multicolumn{7}{|c|}{ Glucuronic acid } \\
\hline $\mathrm{C}-1$ & $4.94(\mathrm{~d}, 7.0)$ & 105.8 & $5.02(\mathrm{~d}, 7.5)$ & 106.0 & $4.94(\mathrm{~d}, 8.0)$ & 105.8 \\
\hline $\mathrm{C}-2$ & $4.43(\mathrm{dd}, 7.0,9.5)$ & 76.8 & $4.18(\mathrm{dd}, 7.5,9.0)$ & 79.4 & $4.44(\mathrm{dd}, 8.0,9.5)$ & 76.8 \\
\hline $\mathrm{C}-3$ & $4.53(t, 9.5)$ & 78.4 & $4.38(t, 9.0)$ & 77.7 & $4.52(t, 9.5)$ & 78.4 \\
\hline C-4 & $4.36(t, 9.5)$ & 74.1 & $4.46(t, 9.5)$ & 73.3 & $4.37(t, 9.5)$ & 74.1 \\
\hline $\mathrm{C}-5$ & $4.55(\mathrm{~d}, 10.0)$ & 77.3 & $4.55(\mathrm{~d}, 9.0)$ & 77.3 & $4.54(\mathrm{~d}, 10.0)$ & 77.3 \\
\hline \multirow[t]{2}{*}{$\mathrm{COOCH}_{3}$} & $3.76(\mathrm{~s})$ & 52.5 & $3.73(\mathrm{~s})$ & 52.4 & $3.76(\mathrm{~s})$ & 52.5 \\
\hline & & 170.7 & & 170.8 & & 170.7 \\
\hline \multicolumn{7}{|l|}{ Arabinose } \\
\hline $\mathrm{C}-1$ & $5.56(\mathrm{~d}, 7.0)$ & 102.2 & $5.89(\mathrm{~d}, 3.0)$ & 101.2 & $5.57(\mathrm{~d}, 8.0)$ & 102.2 \\
\hline $\mathrm{C}-2$ & $4.49(\mathrm{dd}, 7.0,10.5)$ & 78.0 & $4.78(\mathrm{dd}, 3.0,5.0)$ & 75.3 & $4.49(\mathrm{dd}, 8.0,9.0)$ & 78.0 \\
\hline $\mathrm{C}-3$ & $4.02(\mathrm{dd}, 3.5,10.5)$ & 76.1 & $4.47(\mathrm{t}, 5.0)$ & 72.1 & $4.01^{a)}$ & 76.1 \\
\hline C-4 & $4.02^{a)}$ & 70.9 & $4.39^{a)}$ & 67.0 & $4.03^{a)}$ & 70.9 \\
\hline \multirow[t]{2}{*}{$\mathrm{C}-5$} & $3.58(\mathrm{brd}, 12.0)$ & 67.3 & $3.87(\mathrm{dd}, 3.5,11.0)$ & 63.3 & $3.58(\mathrm{brd}, 12.5)$ & 67.3 \\
\hline & $4.14(\mathrm{brd}, 12.0)$ & & $4.63(\mathrm{dd}, 6.5,11.0)$ & & $4.14(\mathrm{brd}, 12.5)$ & \\
\hline \multicolumn{7}{|l|}{ Rhamnose } \\
\hline $\mathrm{C}-1$ & $6.22(\mathrm{~d}, 1.5)$ & 102.8 & $5.80(\mathrm{brs})$ & 102.7 & $6.22(\mathrm{brs})$ & 102.8 \\
\hline $\mathrm{C}-2$ & $4.78(\mathrm{dd}, 1.5,3.5)$ & 72.7 & $4.59^{a)}$ & 72.8 & $4.77(\mathrm{dd}, 1.5,3.5)$ & 72.7 \\
\hline $\mathrm{C}-3$ & $4.64(\mathrm{dd}, 3.5,9.0)$ & 73.1 & $4.55^{a)}$ & 73.0 & $4.64(\mathrm{dd}, 3.5,9.0)$ & 73.1 \\
\hline $\mathrm{C}-4$ & $4.32(t, 9.0)$ & 74.7 & $4.29(t, 9.0)$ & 74.3 & $4.32(t, 9.5)$ & 74.7 \\
\hline $\mathrm{C}-5$ & $4.93^{b)}$ & 69.8 & $4.61^{a)}$ & 70.7 & $4.90^{b)}$ & 69.8 \\
\hline $6-\mathrm{CH}_{3}$ & $1.76(\mathrm{~d}, 6.5)$ & 19.3 & $1.76(\mathrm{~d}, 6.5)$ & 19.2 & $1.76(\mathrm{~d}, 6.5)$ & 19.3 \\
\hline \multicolumn{7}{|c|}{ Arabinose at $\mathrm{C}-22$} \\
\hline $\mathrm{C}-1$ & $4.92(\mathrm{~d}, 7.5)$ & 109.3 & $4.91(\mathrm{~d}, 7.5)$ & 109.1 & & \\
\hline $\mathrm{C}-2$ & $4.53(\mathrm{dd}, 7.5,9.0)$ & 74.3 & $4.54(\mathrm{dd}, 7.5,8.5)$ & 74.4 & & \\
\hline $\mathrm{C}-3$ & $4.12(\mathrm{dd}, 3.5,9.0)$ & 75.8 & $4.11(\mathrm{dd}, 3.5,8.5)$ & 75.8 & & \\
\hline C-4 & $4.24(\mathrm{~m})$ & 70.3 & $4.22(\mathrm{~m})$ & 70.3 & & \\
\hline \multirow[t]{2}{*}{ C-5 } & $3.74(\mathrm{dd}, 1.0,12.5)$ & 68.1 & $3.73(\mathrm{brd}, 12.0)$ & 68.1 & & \\
\hline & $4.32(\mathrm{dd}, 2.5,12.5)$ & & $4.31(\mathrm{dd}, 1.5,12.0)$ & & & \\
\hline
\end{tabular}

a) Overlapping signal. b) Overlapping with HDO signal.

Table 3. ${ }^{13} \mathrm{C}-\mathrm{NMR}$ Data of Aglycon Moieties of 1a, 2a, and 5a

\begin{tabular}{lrrrrrrr}
\hline \hline Carbon no. & \multicolumn{1}{c}{$\mathbf{1 a}$} & $\mathbf{2 a}$ & $\mathbf{5 a}$ & Carbon no. & $\mathbf{1 a}$ & $\mathbf{2 a}$ & $\mathbf{5 a}$ \\
\hline C-1 & 39.0 & 39.2 & 39.0 & C-16 & 28.0 & 28.1 & 27.4 \\
C-2 & 27.0 & 27.1 & 27.0 & C-17 & 39.6 & 39.6 & 38.9 \\
C-3 & 91.4 & 89.7 & 91.4 & C-18 & 44.1 & 44.2 & 43.9 \\
C-4 & 44.3 & 39.8 & 44.3 & C-19 & 41.3 & 41.3 & 41.2 \\
C-5 & 56.4 & 56.0 & 56.4 & C-20 & 41.9 & 42.2 & 41.5 \\
C-6 & 18.9 & 18.8 & 18.9 & C-21 & 71.1 & 71.2 & 69.0 \\
C-7 & 33.2 & 33.0 & 33.2 & C-22 & 93.9 & 93.6 & 81.8 \\
C-8 & 40.5 & 40.6 & 40.5 & C-23 & 23.5 & 28.5 & 23.3 \\
C-9 & 48.1 & 48.2 & 48.1 & C-24 & 63.8 & 17.3 & 63.8 \\
C-10 & 36.8 & 37.2 & 36.8 & C-25 & 16.1 & 16.0 & 16.1 \\
C-11 & 24.5 & 24.2 & 24.4 & C-26 & 17.1 & 17.3 & 17.2 \\
C-12 & 122.8 & 122.9 & 123.4 & C-27 & 27.0 & 27.2 & 26.9 \\
C-13 & 144.9 & 144.9 & 144.2 & C-28 & 23.3 & 23.5 & 22.0 \\
C-14 & 42.2 & 41.9 & 42.2 & C-29 & 71.0 & 71.1 & 71.2 \\
C-15 & 27.0 & 27.0 & 26.8 & C-30 & 17.9 & 17.9 & 17.1 \\
Acetate & & & & & & & 21.6 \\
& & & & & & & 171.3 \\
\hline
\end{tabular}

5a. Therefore the partial structure of the $\mathbf{5 a}$ was determined to be 3- $O$ - $\alpha$-L-rhamnopyranosyl $(1 \rightarrow 2)-\alpha$-L-arabinopyra$\operatorname{nosyl}(1 \rightarrow 2)$ - $\beta$-D-glucuronopyranosyl kudzusapogenol A (subproside II). The position of the acetyl group in 5a was determined by an HMBC experiment, which showed a longrange correlation between the $\mathrm{H}-22$ of the kudzusapogenol A moiety and the carbonyl carbon of the acetyl group. Consequently, the structure of the 5 was determined to be $3-O-\alpha-\mathrm{L}-$ rhamnopyranosyl $(1 \rightarrow 2)$ - $\alpha$-L-arabinopyranosyl $(1 \rightarrow 2)-\beta$-Dglucuronopyranosyl kudzusapogenol A 22-O-acetate.

\section{Experimental}

Melting points were measured on a Mitamura-Riken apparatus and are uncorrected. The optical rotations were determined on a JASCO P-1020 polarimeter. The IR spectra were recorded on a JASCO FT/IR-5300 spectrometer. The FAB mass spectrum was obtained in a 3-nitrobenzyl alcohol matrix in negative-ion mode on a VG-VSEQ spectrometer. The NMR spectra were measured in pyridine- $d_{5}$ on a Bruker AMX-500 instrument, and the chemical shifts were referenced to TMS. GC analysis was performed with a Hewlett Packard 5890 Series II gas chromatograph equipped with an $\mathrm{H}_{2}$ flame ionization detector. The column was HP-5 capillary column $(30 \mathrm{~m} \times$ $0.32 \mathrm{~mm} \times 0.25 \mu \mathrm{m}$ ): column temperature, $200^{\circ} \mathrm{C}$; injector and detector temperature, $290^{\circ} \mathrm{C}$; and $\mathrm{He}$ flow rate, $30 \mathrm{ml} / \mathrm{min}$. TLC was performed on silica gel $60 \mathrm{~F}_{254}$ (Merck) and cellulose plates (Art No. 5716, Merck).

Plant Material The root parts of $S$. koreensis were collected in September 1998 near Yangku City in Kangwon Province, Korea, and authenticated by Dr. T. J. Kim (KRIBB). A voucher specimen (98003) was deposited in the herbarium of the Natural Products Research Institute, Seoul National University.

Extraction and Isolation Dried roots of S. koreensis $(2.6 \mathrm{~kg})$ were extracted three times with $\mathrm{MeOH}$ at room temperature. The $\mathrm{MeOH}$ extract was evaporated under reduced pressure to dryness, which was partitioned in sucession between $\mathrm{H}_{2} \mathrm{O}$ and $n$-hexane, $\mathrm{CH}_{2} \mathrm{Cl}_{2}$, EtOAc, and then $n$ - $\mathrm{BuOH}$, affording 44.9, 209.3, 42.5, and $85 \mathrm{~g}$ of the respective extracts. A portion (13.1 g) of the $n$-BuOH fraction was passed through a porous polymer MCI gel (CHP 20P, 75-150 $\mu$ ) column. After washing the column with $\mathrm{H}_{2} \mathrm{O}$, the adsorbed materials were eluted successively with $20 \%$ and $50 \%$ aqueous $\mathrm{MeOH}$ and $\mathrm{MeOH}$. Fractions were divided into A $\left(\mathrm{H}_{2} \mathrm{O}, 7.5 \mathrm{~g}\right), \mathrm{B}(20 \%$ $\left.\mathrm{MeOH}-\mathrm{H}_{2} \mathrm{O}, 1.5 \mathrm{~g}\right), \mathrm{C}\left(50 \% \mathrm{MeOH}-\mathrm{H}_{2} \mathrm{O}, 1.3 \mathrm{~g}\right)$, or D (MeOH, $\left.1.6 \mathrm{~g}\right)$. Subfraction $\mathrm{D}$, which was rich in saponins, was methylated with $\mathrm{CH}_{2} \mathrm{~N}_{2}$ to yield the methylated saponin fraction (MD). A portion of the MD fraction $(312 \mathrm{mg})$ was subjected to column chromatography on RP-18 eluted with $\mathrm{MeOH}-\mathrm{H}_{2} \mathrm{O}(7: 3)$ to give subfractions MD $1-6$. Fraction MD-2 (120 mg) was then chromatographed on silica gel 60 using EtOAc saturated with $\mathrm{H}_{2} \mathrm{O}$ with increasing amounts of $\mathrm{MeOH}$ as eluent to give compound 1a (11 mg) and a mixture of compounds $\mathbf{2 a}$ and $\mathbf{3 a}(100 \mathrm{mg})$. The mixture of $\mathbf{2 a}$ and $\mathbf{3 a}$ 
was repeatedly chromatographed on LiChroprep RP-18 with $80 \% \mathrm{MeOH}$ as eluent to yield saponins 2a $(8 \mathrm{mg})$ and then $\mathbf{3 a}(8 \mathrm{mg})$. Fraction MD-3 (31 mg) was rechromatographed on a silica gel column using $\mathrm{CHCl}_{3}$ $\mathrm{MeOH}-\mathrm{H}_{2} \mathrm{O}$ ( $7: 3: 1$, lower layer) and repeated LiChroprep RP-18 column chromatography using a $\mathrm{MeOH}-\mathrm{H}_{2} \mathrm{O}$ gradient solvent system to afford $\mathbf{4 a}$ $(9 \mathrm{mg})$ and $\mathbf{5 a}(6 \mathrm{mg})$. Similarly, fraction MD-4 (63 mg) was subjected to reverse-phase column chromatography with the same solvent as for $\mathbf{4 a}$ and $\mathbf{5 a}$ and further purified on Sephadex LH-20 eluted with $\mathrm{MeOH}$ to afford 6a $(11 \mathrm{mg})$ and $7 \mathbf{a}(10 \mathrm{mg})$. Spectra (NMR and FAB-MS) measured for the isolated saponins of known structure were in good agreement with the reported data for sophoraflavoside I (3) ${ }^{23)}$ kudzusaponin $\mathrm{SA}_{3}(\mathbf{4}) .{ }^{24)}$ subproside II (6), ${ }^{25)}$ and azukisaponin $\mathrm{V}(7){ }^{26-28)}$

Echinosophoroside $\mathrm{A}_{1}$ methyl ester (1a) was obtained as an amorphous powder $(\mathrm{MeOH}),[\alpha]_{\mathrm{D}}^{20}+8.6^{\circ}(c=0.34, \mathrm{MeOH})$. (-)-HR-FAB-MS $m / z$ : 1089.5479. Calcd for $\mathrm{C}_{53} \mathrm{H}_{85} \mathrm{O}_{23}:$ 1089.5482. ${ }^{1} \mathrm{H}-\mathrm{NMR}$ (pyridine- $d_{5}$, $500 \mathrm{MHz}$ ): Tables 1 and $2 .{ }^{13} \mathrm{C}-\mathrm{NMR}$ (pyridine- $d_{5}, 125.8 \mathrm{MHz}$ ): Tables 2 and 3.

Echinosophoroside B methyl ester (2a) was obtained as an amorphous powder $(\mathrm{MeOH}),[\alpha]_{\mathrm{D}}^{20}+31.4^{\circ}(c=0.25, \mathrm{MeOH})$. (-)-HR-FAB-MS $m / z$ : 1073.5520. Calcd for $\mathrm{C}_{53} \mathrm{H}_{85} \mathrm{O}_{22}:$ 1073.5533. ${ }^{1} \mathrm{H}-\mathrm{NMR}$ (pyridine- $d_{5}$, $500 \mathrm{MHz}$ ): Tables 1 and 2. ${ }^{13} \mathrm{C}-\mathrm{NMR}$ (pyridine- $d_{5}, 125.8 \mathrm{MHz}$ ): Tables 2 and 3.

Acetyl-subproside II methyl ester (5a) was obtained as an amorphous powder $(\mathrm{MeOH}),[\alpha]_{\mathrm{D}}^{20}+8.7^{\circ}(c=0.314, \mathrm{MeOH})$. (-)-HR-FAB-MS $m / z$ : 999.5160. Calcd for $\mathrm{C}_{50} \mathrm{H}_{79} \mathrm{O}_{20}: 999.5165 .{ }^{1} \mathrm{H}-\mathrm{NMR}$ (pyridine- $d_{5}, 500 \mathrm{MHz}$ ): Tables 1 and $2 .{ }^{13} \mathrm{C}-\mathrm{NMR}$ (pyridine- $d_{5}, 125.8 \mathrm{MHz}$ ): Tables 2 and 3.

Acid Hydrolysis of 1a, 2a, and 5a Saponins 1a, 2a, and 5a (1 mg each) were refluxed separately with $5 \% \mathrm{HCl}$ in $60 \%$ aqueous dioxane $(10 \mathrm{ml})$ for $2 \mathrm{~h}$. The reaction solution was evaporated under reduced pressure, and the hydrolysate was extracted with ether. The ether extract was evaporated to yield the aglycon kudzusapogenol A from 1a and 5a and abrisapogenol $\mathrm{C}$ from $\mathbf{2 a}$, which was identified by direct comparison with an authentic sample. The $\mathrm{H}_{2} \mathrm{O}$ layer was neutralized with $\mathrm{Ag}_{2} \mathrm{CO}_{3}$, filtered, and the filtrate was concentrated under reduced pressure. The residue was compared with standard sugars using cellulose TLC [pyridine-EtOAc- $\mathrm{HOAc}-\mathrm{H}_{2} \mathrm{O}$ (36: $36: 7: 21)]$, which showed the sugars to be arabinose, rhamnose, and glucuronic acid in all cases.

Determination of the Absolute Configuration of Sugars of 1a, 2a, and 5a The absolute configuration of glucuronic acid was determined after $\mathrm{NaBH}_{4}$ reduction as described in the literature. ${ }^{29)}$ To a solution of $\mathbf{1 a}(1 \mathrm{mg})$ in $\mathrm{MeOH}$ was added $\mathrm{NaBH}_{4}$, and the mixture was kept at room temperature for $30 \mathrm{~min}$. The reaction mixture was worked up with MCI gel CHP 20P. The $\mathrm{MeOH}$ eluate was treated as above, and the dried sugar mixture was dissolved in pyridine $(0.1 \mathrm{ml})$, and then the solution was added to a pyridine solution $(0.1 \mathrm{ml})$ of L-cysteine methyl ester hydrochloride $(2 \mathrm{mg})$ and warmed at $60^{\circ} \mathrm{C}$ for $1 \mathrm{~h}$. The solvent was evaporated under a $\mathrm{N}_{2}$ stream and dried in vacuo. The residue was trimethylsilylated with TMS-HT $(0.1 \mathrm{ml})$ at $60^{\circ} \mathrm{C}$ for $30 \mathrm{~min}$. After the addition of $n$-hexane and water, the $n$-hexane layer was removed and checked by GC. The retention times $\left(t_{\mathrm{R}}\right)$ of the peaks were $18.24 \mathrm{~min}$ (L-arabinose), $23.73 \mathrm{~min}$ (L-rhamnose), and $37.87 \mathrm{~min}$ (D-glucose). Saponins 2a and 5a were treated as 1a, and the absolute configurations of sugars were also the same form as those of 1a.

Acknowledgments This work was supported by the grant (PF032030200) from the Plant Diversity Research Center of the 21 st century Frontier Research Program funded by the Ministry of Science and Technology of Korea.

\section{References and Notes}

1) International Legume Database \& Information Service: 〈http:// www.biodiversity.soton.ac.uk/LegumeWeb $\rangle$.

2) Lee T. B., "Illustrated Flora of Korea," Hyangmoon Publishing Co., Seoul, 1989, p. 466.

3) Kim C. M., Ebizuka Y., Sankawa U., Chem. Pharm. Bull., 37, 28792881 (1989).

4) Iinuma M., Ohyama M., Tanaka T., Mizuno M., Hong S.-K., Phytochemistry, 30, 3153-3154 (1991).

5) Iinuma M., Ohyama M., Tanaka T., Mizuno M., Hong S.-K., Phytochemistry, 31, 665-669 (1992).

6) Iinuma M., Ohyama M., Tanaka T., Mizuno M., Hong S.-K., Phytochemistry, 31, 2855-2858 (1992).

7) Kim J. S., Byun J. H., Kang S. S., Son K. H., Kim H. P., Chang H. W., Kor. J. Pharmacogn., 33, 110-115 (2002).

8) Kim C. M., Kang S. S., Yakhak Hoeji, 30, 139-142 (1986).

9) Murakoshi I., Fukuchi K., Haginiwa J., Ohmiya S., Otomasu H., Phytochemistry, 16, 1460-1461 (1977).

10) Murakoshi I., Watanabe M., Haginiwa J., Ohmiya S., Otomasu H., Phytochemistry, 21, 1470-1471 (1982).

11) Murakoshi I., Kidoguchi E., Kubota M., Haginiwa J., Ohmiya S., Otomasu H., Phytochemistry, 21, 2385-2388 (1982).

12) Murakoshi I., Watanabe M., Okuda T., Kidoguchi E., Haginiwa J., Ohmiya S., Otomasu H., Phytochemistry, 24, 2707-2708 (1985).

13) Kang S. S., Kim C. M., Arch. Pharm. Res., 10, 67-68 (1987).

14) Sakamoto S., Kuroyanagi M., Ueno A., Sekita S., Phytochemistry, 31, 1339-1342 (1992).

15) Arao T., Kinjo J., Nohara T., Isobe R., Chem. Pharm. Bull., 45, 362366 (1997).

16) Kinjo J., Miyamoto I., Murakami K., Kida K., Tomimatsu T., Yamasaki M., Nohara T., Chem. Pharm. Bull., 33, 1293-1296 (1985).

17) Hara S., Okabe H., Mihashi K., Chem. Pharm. Bull., 35, 501-506 (1987).

18) Seo S., Tomita Y., Tori K., Yoshimura Y., J. Am. Chem. Soc., 100, 3331-3339 (1978).

19) Sakai Y., Takeshita T., Kinjo J., Ito Y., Nohara T., Chem. Pharm. Bull., 38, 824-826 (1990).

20) Ishii H., Kitagawa I., Matsushita K., Shirakawa K., Tori K., Tozyo T., Yoshikawa M., Yoshimura Y., Tetrahedron Lett., 22, 1529-1532 (1981).

21) Nikaido T., Koike K., Mitsunaga K., Saeki T., Nat. Med., 52, $54-59$ (1998).

22) Kuroda M., Mimaki Y., Ori K., Koshino H., Nukada T., Sakagami H., Sashida Y., Tetrahedron, 58, 6735-6740 (2002).

23) Yoshikawa M., Wang H. K., Kayakiri H., Taniyama T., Kitagawa I., Chem. Pharm. Bull., 33, 4267-4274 (1985).

24) Arao T., Kinjo J., Nohara T., Isobe R., Chem. Pharm. Bull., 43, 1176 1179 (1995).

25) Ding Y., Takeshita T., Yokoyama K., Kinjo J., Nohara T., Chem. Pharm. Bull., 40, 139-142 (1992).

26) Kitagawa I., Wang H. K., Saito M., Yoshikawa M., Chem. Pharm. Bull., 31, 683-688 (1983).

27) Kang S. S., Lee Y. S., Lee E. B., Arch. Pharm. Res., 11, 197-202 (1988).

28) Kang S. S., Ahn B. T., Kim J. S., Bae K. H., J. Nat. Prod., 61, 299300 (1998).

29) Tanaka R., Nagao T., Okabe H., Yamauchi T., Chem. Pharm. Bull., 38, 1153-1157 (1990). 